\title{
EFFECTIVENESS OF MARKETING STRATEGIES ON ENHANCING CULTURAL TOURISM: A CASE STUDY ON TABAKA SOAPSTONE CARVINGS IN KISII REGION, KENYA
}

\author{
Henry Nyamogosa \\ Great Lakes University of Kisumu, \\ Department of Hospitality \& Tourism \\ P.O. Box 2224-40100, Kenya
}

Kisumu.

\author{
Michael Murimi \\ Great Lakes University of Kisumu, \\ Department of Hospitality \& Tourim \\ P.O. Box 2224-40100, \\ Kisumu, Kenya
}

Article DOI: https://doi.org/10.36713/epra3011

\begin{abstract}
Cultural Tourism is a growing phenomenon around the world. In Kenya, cultural tourism represents an important part of the tourism sector and largely depends on cultural heritage assets such as traditions, artifacts, and crafts, historical buildings, and gastronomy of host people. While marketing strategy can enhance the number of visitation and revenues to these sites, other strategies may be ineffective to meet the aims of the cultural sites. Investigating the effectiveness of marketing strategies on enhancing cultural Tourism should play a role in enhancing visitation levels. To this end, some authors have suggested marketing strategies for enhancing visitation levels in cultural sites; however, research on the effectiveness of marketing strategies in cultural sites is limited. To address this research gap, the research sought to examine the effectiveness of promotion, price, and brand awareness as marketing strategies on enhancing cultural tourism in Kenya using a case study on Tabaka soapstone carvings. The target population consisted of 300 tourists, 30 employees at the site, and management of the cultural site committee. A stratified sampling technique was used to select 60 tourists while 10 employees were selected through a proportionate sampling technique. Data was collected from both secondary and primary sources. However, the researcher relied mostly on primary sources as it was taken to be accurate as compared to secondary sources. The major tool for the collection of data from tourists and employees was structured questionnaire, while, data from the management was collected via interview. Analysis of data was done descriptively and presented by tables and figures. Limitations of the study were also explored and ethics considered in the study. The study found out that an inadequate number of tourists visiting the site were as a result of ineffective communication techniques employed. Tourism products and services were not presented well to tourists as it was promised to them thus leading to low satisfaction of tourists. They had also developed a perception that the price charged at the site was expensive. The study farther found out that tourists were unable to distinguish the cultural site from others due to unclear logos on site's brochures, websites, and signboards. The study recommended that cultural site management should use websites and local radio stations to enable more target tourists to discover the site instead of tourists depending on friends and relatives as revealed by the study. Offers and discounts during weekdays should be encouraged to enhance visitation during such periods.
\end{abstract}




\subsection{INTRODUCTION}

Cultural tourism is a form of tourism that deals with the culture of a country or region. It specifically highlights people's lifestyles regarding their food, art, fashion, architecture, buildings, and other elements that assisted people to shape their culture (Riddhagni \& Taylor, 2019). Chen \& Rahman (2018) suggest that cultural tourists spend more money as compared to any other type of tourists while in a tourist destination. With the current increase in commodification of cultural products, cultural tourism is becoming much popular in the world as compared to other forms of tourism (AlGarni, 2020). Throughout the world, cultural experiences are sought by tourists who travel from one region or site to another. For example, tourists may travel from Egyptian pyramids to cathedrals of Europe, travel to Fort Jesus in Mombasa, Kenya to cosmopolitan streets of New York. Most countries in the world are focusing on cultural tourism for the growth of their tourism industry. Kenya is one of the countries focusing on cultural tourists as their target market to accelerate its growth in the tourism industry. For a long time, Kenya has promoted its wildlife and beaches as the resources to attract tourists but this has greatly changed in recent times. Kenya is diversifying its tourism products and culture is one of the products that has been developed, packaged, and promoted to the target tourists.

The development of cultural tourism needs a commitment and an investment as it is an incremental process. High financial resources and superior human expertise are needed to develop, package, promote, and sell cultural products of a region, site, or area. Unfortunately, not every community can have the required resources to utilize cultural resources effectively. In the past decade, the tourism industry was considered as having market-ready products for tourists. The marketing of tourism products such as culture was never part of tourist destination management's efforts to develop the destination. Most tourist sites focused on the protection and preservation of history, culture, and natural resources. However, in the current world, tourist sites are promoting and marketing their tourism products to attract new target markets.

Kenya is predominated with nature-based tourism that involves wildlife in the southern part of the country and beaches found along the Indian Ocean. This implies that few regions attract a good number of tourists in Kenya, hence making tourism in Kenya to be spatial. According to the Kenya Tourist Board (2018), the Kisii region received 3\% of international tourists as compared to the Coast region that received $65 \%$. Therefore, the study aims to examine the effectiveness of marketing strategies to enhance cultural tourism in the Kisii region, with a key focus on the Tabaka soapstone cultural site. Foroudi et al. (2020) suggest that the success of a cultural site is connected to effective marketing strategies and positive image. The ways destination assemblies and presents tourism products to its tourists have an overall effect on the repeat of such tourists to a destination. A product in a marketing sense is the core benefit provided or the core problem solved. In this study, Tabaka Soapstone is the product and the core benefit from the cultural site is the historical experience. The strategies involved in developing, packaging, promoting, and selling the cultural site experiences to tourists will determine the number of tourists arriving in the destination. In the case of a cultural site, the core benefit is to provide deep historical experience, and then how the product is shaped will be different than if the core benefit desired is a more secular one. One should focus on one or two core benefits and then communicate those benefits to the target audience (Fader, 2020). However at Tabaka cultural soapstone in the Kisii region, management has been focusing on selling arts as a whole to tourists through intermediaries, hence there was a need to examine how they market their products, and who our target market to Tabaka soapstone site.

Any cultural site aims to receive more target tourists who will remain friendly to the local community and have no negative impact on the resource visited. For Tabaka soapstone carvings site to receive more tourists, it has to identify its products, competitors, and those it will not compete in (Foroudi et al., 2020). An appropriate marketing strategy that aims at meeting tourist's needs and demands should be designed. This would enhance the number of tourists arriving at the cultural site. According to Kenya Tourist Board (2018), visitation to the western circuit which includes Tabaka soapstone carvings is $3 \%$ of international Tourists compared to the coast which is $65 \%$. Inappropriate marketing strategies are thought to contribute to low visitation levels. Given this discrepancy, there was a need to investigate the effectiveness of marketing strategies in enhancing cultural Tourism in the Kisii region, in Kenya. This would improve the visitation of tourists to the region thus enhancing the living standards of local people.

\subsection{SIGNIFICANCE OF THE STUDY}

The study's purpose is to identify the effectiveness of marketing strategies to enhance the number of visitations to the Kisii region, Kenya. This, in turn, will improve the cultural tourism in the western circuit. 


\subsection{OBJECTIVES}

The objectives of this study were:

1. To identify the effectiveness of promotion on enhancing cultural tourism in Tabaka soapstone carvings at the end of the study.
2. To identify the effectiveness of price strategy on enhancing cultural tourism in Tabaka soapstone carvings at the end of the study.

3. To identify the effectiveness of brand awareness on enhancing cultural tourism in Tabaka soapstone carvings at the end of the study

\section{CONCEPTUAL FRAMEWORK MODEL}

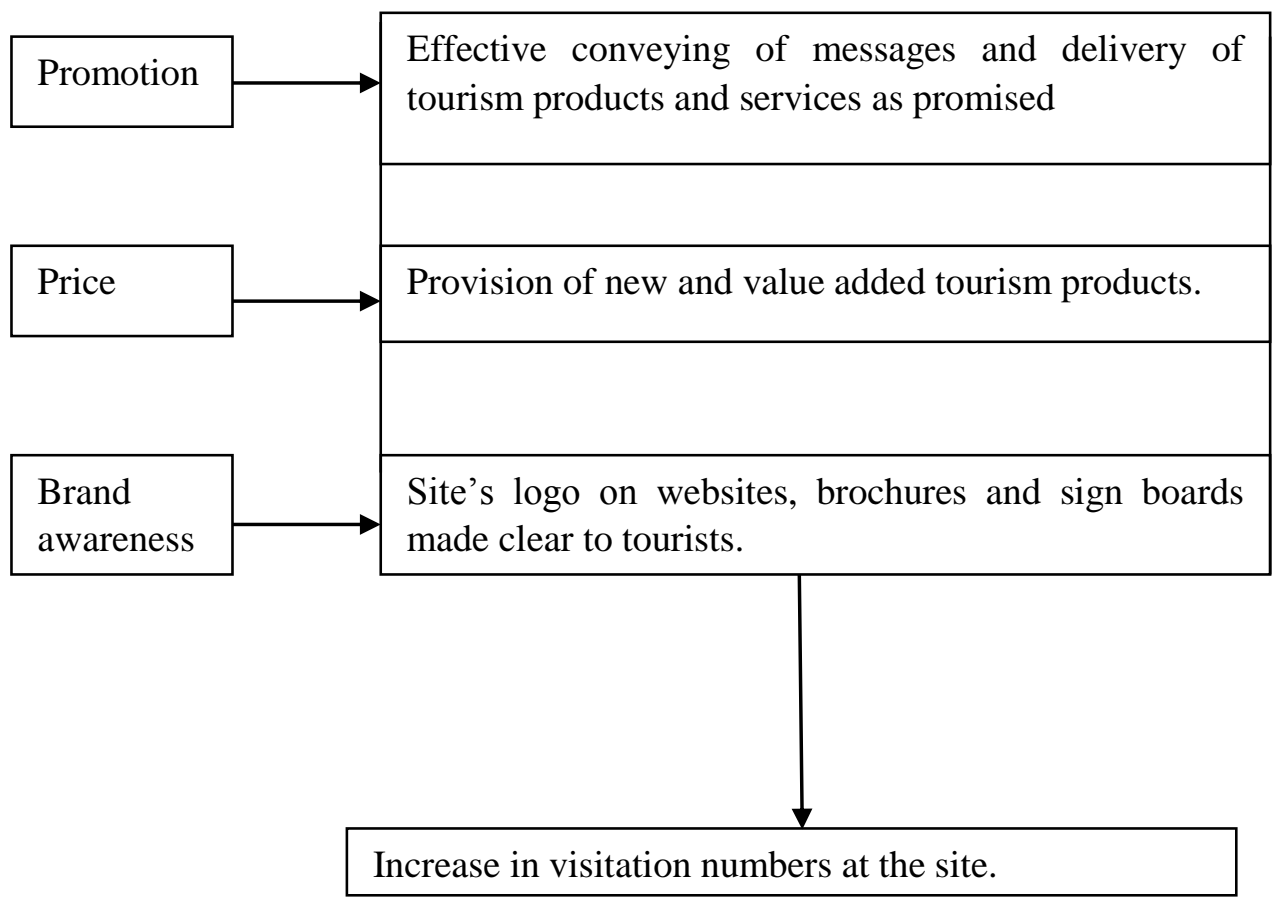

Source: Authors, 2020.

\section{LITERATURE REVIEW \\ 2.1 HISTORICAL DIMENSION}

Arrivals of tourists in Africa have been low in the last decade as compared to other continents such as the United States of America and Europe. According to United Nations World Tourism Organization (2020), France, Spain, and United States topped the list in the international tourists' arrivals while no African country featured in the top ten list of countries leading in international tourists' arrivals. This implies that Africa as a continent has not tapped into potentials of tourism in the current era of globalization. Unfortunately, African countries such as South Africa, Mozambique, Tanzania, and Kenya are greatly dependent on tourism for their economic growth. There are many tourism resources that African countries such as Kenya need to exploit to enhance their international tourists' arrivals. 
The Kenyan tourism industry is ranked as the fastest growing industry and the second highest foreign exchange earner after tea (Steinmetz, 2020). In the year 2019, the tourism industry earned Ksh 163.56 billion from Ksh 157 billion in the year 2018 with international tourists' arrivals increasing by $1.167 \%$ (Steinmetz, 2020). The Kenyan government attributed the increase of earnings from the tourism industry to effectively market strategies carried out by the Kenya Tourist Board.

\subsection{PROMOTION AND CULTURAL TOURISM}

Diarta (2017) defines promotion as a marketing mix element that enables marketers to educate, convince or remind consumers and other business to business users of a product of a firm with aim of influencing their opinion or eliciting a response. A tourist destination creates awareness of its product through performing promotion activities such as placing ads on social media platforms, designing flyers, promoting through local radio or televisions. According to Walker and Moscardo (2016), promotion increases demand a product and can as well act as an accessibility control tool in a cultural site. Accessibility in this study implies access to information regarding Tabaka Soapstone by the audience through advertising material and media promotions. Camilleri (2018) suggests that promotion entails selecting target tourists of a tourist destination, position, and integrate different tools of communication to deliver the intended message. Unfortunately, Tabaka soapstone depends on middlemen to sell tourists' products that it develops. This implies that the Tabaka Soapstone site management has not devised an effective promotional strategy to increase the number of tourists visiting the site.
The site is managed and run by the community members, majority of host community members could not see benefits of the site and thus may lead to them to withdraw their support from the site and join different enterprises that earn more revenue as compared to depending on a low number of tourists' arrivals at the site. According to Morrison (2018), a destination management organization need to know its customer better for it to perform well. This implies that effective promotion begins with a good tourist database management system that identifies potential tourists to the cultural site. Hamed (2017) suggests that destination organization management should retrieve information regarding their customers and align their tourism product and service promotion to the particular needs and preferences of the target market. This, in turn, will influence tourists' opinion and elicit their response to visiting the destination. All the authors agree that promoting a tourist destination such as Tabaka Soapstone cultural site would increase tourist visitation. However, there exists a gap in the effectiveness of promoting activities to enhance tourist visitation. Therefore, the study sought to examine the effectiveness of the promotional activities of the Tabaka Soapstone cultural site to enhance cultural tourism in the Kisii region, Kenya. .

\subsection{BRAND AWARENESS}

Brand refers to the perception and feelings of consumers regarding a particular product and its performance (Almeyda-Ibáñez \& George, 2017). It entails all things of a product or service that have meaning to consumers. According to Della Corte and Aria (2016), branding is a source of competitive advantage for tourist destinations that have embraced it. Bassano et al (2019) support Della Corte and Aria (2016) by highlighting that tourist destinations use branding to differentiate themselves from competitors and earn a prominent place in the minds of their tourists. Branding, according to Foroudi et al (2016), increases tourist loyalty for a tourist destination. Tabaka soapstone carvings have not bundled tangible and intangible attributes that should be associated with the brand to meet the guest's needs and wants. Thus, it is unable to develop positive brand associations. The features being branded must be presented as a singleminded product to make the brand work effectively. 
The authors above agree that the image and quality of brands should match the expectations and perceptions of the consumer and evolve dynamically concerning the changing environment. However, the authors did not highlight the effectiveness of brand awareness in enhancing visitation to a cultural site such as Tabaka Soapstone. In developing a destination brand, destination management should recognize all contact points of the tourists and convey an appropriate message that will enable them to put the visited cultural site on the prominent place of their minds. Each brand contact should deliver a message, whether good, bad, or indifferent. The destination should aim at delivering a consistent and positive message with each contact. Therefore, the study sought to examine the effectiveness of brand awareness in enhancing visitation to the Tabaka soapstone cultural site in the Kisii region.

\subsection{PRICE STRATEGY}

Neuts (2020) defines price as the amount of money consumers need to pay to acquire products. Price plays both tactical and economic role for the tourist destination (Gibbs, 2018). According to Faith and Agwu (2018), the price charged over a given product reflects the value of the product being provided and commensurate with the quality of experience. Ei and Karamanis (2017) found out that people travel to exotic places to perform specialist cultural tours and pay whatever amount asked when they perceive that the value of the product or service provided is equal or greater as compared to the cost. Lutz and Newlands (2018) argue that price can be utilized to democratize or discriminate experiences provided to tourists. This implies that low prices charged for entry to a cultural site such as Tabaka Soapstone may facilitate access for all. Whereas a high price charged for entry to a cultural site would discourage some people from visiting the cultural site and if the price is extremely high, it may exclude some people from visiting the cultural site based on economic grounds. This could justify the reason Tabaka soapstone carvings are receiving a low number of domestic tourists. Novais, Ruhanen, and Arcodia (2018) suggest that a destination organization management can set a competitive price in a particular segment through a well-defined positioning price strategy.
A change in the price level from premium to super-premium may need alteration of product, change of customers, and change of promotion and distribution channels. This implies that altering the price charged in a cultural site can change all other marketing mixes dramatically. Tabaka soapstone carvings site cannot complete with international tourist destinations if looks and operates in a local economy. Authors agree that setting a price strategy on enhancing the sale of the product, in this case increasing visitation of tourists to a cultural site depends on other elements of the marketing mix and market conditions. However, the authors do not address the effectiveness of price strategy in increasing visitation to cultural sites. Price decisions do not incur costs in sales but assist in determining the level of revenue achievable. In most instances, cultural sites would encourage visitation by discounting their entry fees or services to move unsold tourist products. Therefore, this study tried to identify the effectiveness of price strategy at Tabaka soapstone on cultural tourism in the Kisii region.

\subsection{SUMMARY of the literature review and knowledge gap}

It has been observed that most cultural tourist destinations that depend on intermediaries to promote their product end up receiving a low number of tourists thus generating low revenue. Creating brand awareness and building preference and loyalty among cultural tourists would enhance the number of tourists visiting a cultural site without necessarily depending on seasonality. Entry fees, tourists' product prices must be favorable to the target market so as to enable them to perceive activities and products as equivalent to their money paid.

The researcher under this study identified the effects of depending on intermediaries to promote cultural site's products and recommended appropriate ways of promoting a cultural site. The researcher also determined appropriate procedures of creating cultural site's brand and building of preference and loyalty among cultural tourists to avoid destinations depending on seasonality. Appropriate pricing methods were also suggested in the study to avoid discriminating cultural tourists who may not be able to participate in enhancing cultural tourism.

\subsection{METHODOLOGY}

A case study was employed to conduct the research. Case study holistically describes and analyses of a single entity. The case study enabled the study of the Tabaka Soapstone cultural site's effectiveness of marketing strategies in detail. Due to the time limit in examining dependent variables (marketing strategies), it was better to adopt a case study as it uses smaller 
samples for in-depth analysis. The target population of this study included management of cultural site's committee, three hundred tourists, and sixty employees of cultural sites. From the 300 tourists, stratified sampling was employed to select 60 participants in line with Kock and Haday's (2018) recommendation that a minimum sample of $20 \%$ is enough for educational research that has less than 1000 members as a target population. Proportionate sampling was used to select 10 employees from 30 (see table 3.1.).

The study used a structured questionnaire to collect data from employees and tourists at Tabaka Soapstone cultural site. An interview was used to collect data from the management of a committee of cultural sites. The interview was used in the study because it provides high response quality with low refusal rates. Also, a structured interview was used because it is a multi-method data collection that involves cross-examining, questioning, and probing techniques (Lancaster, 2017). The structured interview enabled the researcher to seek more details from the cultural site management regarding their marketing strategies effectively to increase the number of tourists.

Table 3.1:

Sampling size matrix

\begin{tabular}{lcc}
\hline Description & Population & Sample Size \\
\hline Employees & 30 & 10 \\
Tourists & 300 & 60 \\
Management of committee on cultural site & 1 & 1 \\
\hline Total & $\mathbf{3 6 1}$ & $\mathbf{7 1}$ \\
\hline
\end{tabular}

Source: Authors, 2020

\subsection{DATA ANALYSIS AND \\ INTERPRETATION \\ Demographic Information}

Demographic information was based on gender, academic qualification, occupation, age, and the length of stay of the respondent in the cultural site. The demographic data of the respondents were analyzed by the use of quantitative analysis. The cultural site is visited by both male (58\%) and female (42\%) counterparts that came to engage in different activities in the site. The total number of male tourists used in this study was 35 while female tourists were 25 .

Table 4.1.

Gender representation of tourists

\begin{tabular}{ccc}
\hline Male & Female & Total \\
$35(58 \%)$ & $25(42 \%)$ & $60(100 \%)$ \\
\hline
\end{tabular}

Source: Authors, 2020

disparity had no effect in marketing strategies on

The result reveals that, there is no greater disparity in enhancing cultural Tourism. gender in visiting the tourist site. Therefore gender

\section{Level of education}

Table 4.3 Tourists' level of education

\begin{tabular}{llll} 
Primary & Secondary & Tertiary/University & Total \\
\hline $8(13 \%)$ & $20(33 \%)$ & $32(53 \%)$ & 60 \\
\hline
\end{tabular}

Most tourists who visited the site had university /tertiary qualification (53\%). Less than half were either in secondary school or had completed $(33 \%)$.

Less than a quarter numbers of tourists that visited the site had only reached primary level of study $(13 \%)$. From table 4.3 above, it is evident that tourists who had attained the highest level of learning visited the site most.

\section{Employees' length of stay at the cultural site}

The Table 4.4 below indicates the length of time that each employee had been in the cultural site before the 
study was carried out. This was to find out whether marketing strategies were formulated. employee had been in the cultural site when the current

Table 4.4 Employees' length of stay at the cultural site

\begin{tabular}{lll} 
Years & Number of employees & Percentage \\
\hline Less than 1 year & 1 & $10 \%$ \\
1 year & 0 & 0 \\
2 years & 1 & $10 \%$ \\
3 years & 2 & $20 \%$ \\
More than 3 years & 6 & $60 \%$ \\
Total & 10 & $100 \%$ \\
\hline
\end{tabular}

From table 4.4 above majority of employees had stayed at the cultural site for more than three years $(60 \%)$. This indicates that most are aware of the marketing strategies which have been in place. They therefore possess more information concerning the site.

\section{RESULTS OF THE ANALYSIS}

The analysis of data in this section was presented descriptively. The results have been presented as per objectives and research questions of the research study. The results have been presented by use of tables, graphs and percentages.

\subsection{Effectiveness of promotion on enhancing cultural tourism in Kisii region}

Effectiveness of promotion findings of the cultural site are based on tourists' discovery of the site, tourists' motivations to the site, tourists' satisfaction at the site, attractiveness of marketing strategies..

\subsubsection{Tourists' discovery of the site}

Table 4.5 below indicates the means of communication that enabled the tourists to discover Tabaka cultural site. This was to find out whether the form of communication used reached more target tourists in an effective manner.

\begin{tabular}{lll} 
Means of communication & Number of Tourists & Percentage \\
\hline Friend/Relative & 39 & $65 \%$ \\
Radio/Television & 0 & 0 \\
Newspaper & 6 & $10 \%$ \\
Website & 15 & $25 \%$ \\
Other & 0 & 0 \\
Total & 60 & $100 \%$ \\
\hline
\end{tabular}

Source: Authors, 2020

From table 4.5 above, most tourists discovered the cultural site through relatives and friends (65\%). A quarter of the tourists knew the site through websites $(25 \%)$ while less than a quarter of tourists discovered through newspapers $(10 \%)$. It is evident therefore to say that an inadequate number of tourists visiting the cultural site is due to ineffective communication techniques used.

According to the Republic of Kenya (2020), creating awareness of local cultural sites among local people is a core development issue and a goal in its own right. The government of Kenya has developed a community education program that aims at providing local people with the importance of visiting their attractions. They have facilitated county events that aim at making attractions known to local people. From the study, it is evident to say that serious attention is needed in selecting the appropriate media in reaching target tourists of the cultural site.

\subsubsection{Tourists' motivations to the site}

Figure 4.1 below indicates the driving factors that made tourists to visit the cultural site. This was to find out whether the message conveyed out to tourists in regard to attractions and activities was effective. 


\section{Figure 4.1 Tourists' motivations to the site}

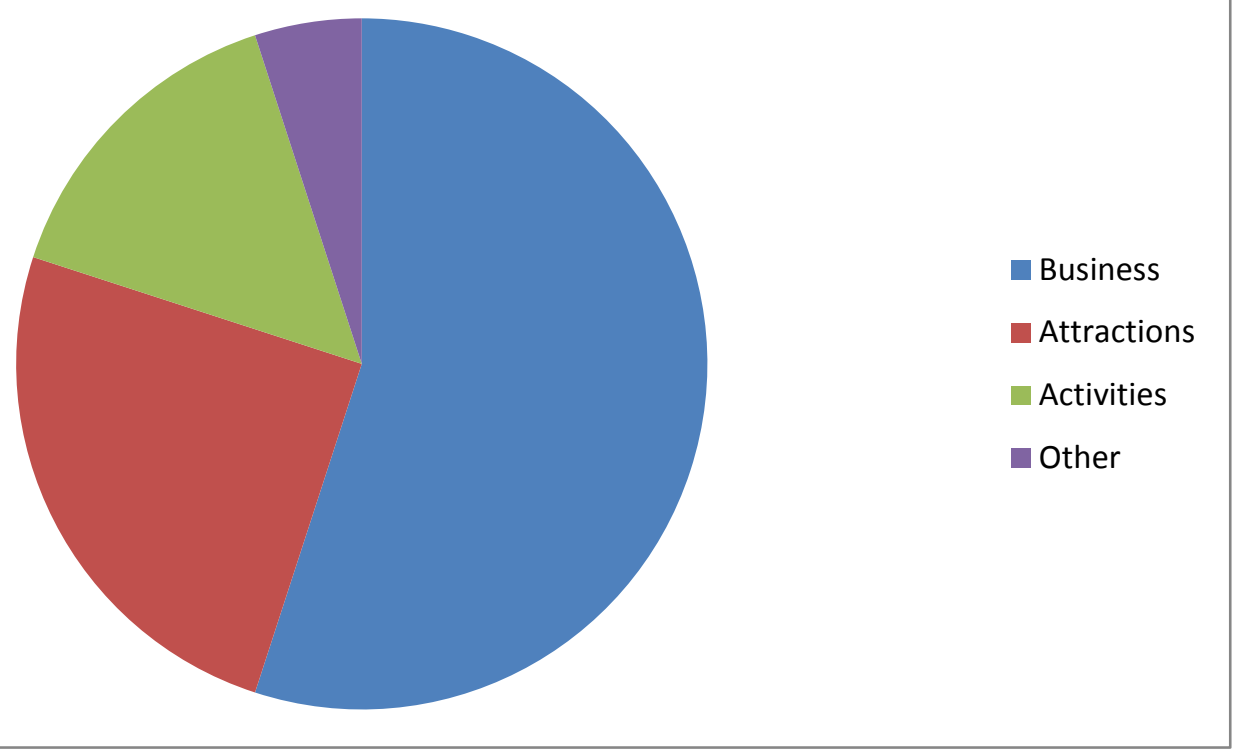

Source: Authors, 2020

From figure 4.1 above the majority of the tourists visiting the cultural site for business purposes $(55 \%)$. A quarter of the tourists visited the site to view attractions $(25 \%)$ while less than a quarter of tourists came for tourists' activities (15\%). A very little number of tourists came for different reasons such as learning the art of making tourists' souvenirs using soapstone and Gusii farming practices (5\%). It is evident, therefore, to say that the cultural site's attractions and activities have not been communicated well to the target tourists.
According to Li, Huang, and Duan (2017), promotion is used to increase demand, and deliver information surrounding a site. From this study, it is evident to say that appropriate identification of cultural site's attractions and activities should be done and communicated well to target tourists.

\subsubsection{Tourists' satisfaction at the site}

Table 4.6 below indicates acceptance of satisfaction by the tourists that visited the site. This was to find whether the tourists met their expectation at the site.

Table 4.6 Tourists' satisfaction at the site

\begin{tabular}{lll} 
Respondent & Number of tourists satisfied & Percentage \\
\hline Yes & 15 & $25 \%$ \\
No & 45 & $75 \%$ \\
Total & 60 & $! 00 \%$ \\
\hline
\end{tabular}

From table 4.6 above, the majority of tourists that visited the site were not satisfied $(75 \%)$ by the services offered. Only a quarter of tourists were satisfied $(25 \%)$ by the services offered. It is evident, therefore, to say that tourism products and services were not well presented to tourists as it was promised to them before.

\subsection{Effectiveness of price on enhancing cultural tourism}

Effectiveness of price findings of the cultural site is based on tourists' favorable time to visit the site, the price charged for site's products and services offers at low season, and employees' rate on motivating factors to visit the site. The data was collected from Tabaka soapstone cultural site as explained by the figure and tables below. 


\subsubsection{Tourists' favorable time to visit the cultural site.}

Table 4.7 below indicates the preferred time by tourists to visit the cultural site. This was to find whether tourists took advantage of time when products and services were lowly charged.

Table 4.7 Tourists' favorable time to visit the cultural site.

Time Number of tourists

Percentage

Holidays

15

Weekends

33

Week days

12

$25 \%$

$55 \%$

Total

60

$20 \%$

$100 \%$

From table 4.7above, most of tourists visited the site during weekends $(55 \%)$ while a quarter visited during holidays $(25 \%)$. A few number of tourists visited during week days $(20 \%)$. It is evident therefore to say that the cultural site had not put measures to attract tourists during week days.
4.3.2Tourists' view on Price charged at the site

Figure 4.2 below indicates the view of tourists on price at which tourism products and services were charged at the cultural site. This was to find out whether the price charged was affordable to the target tourists

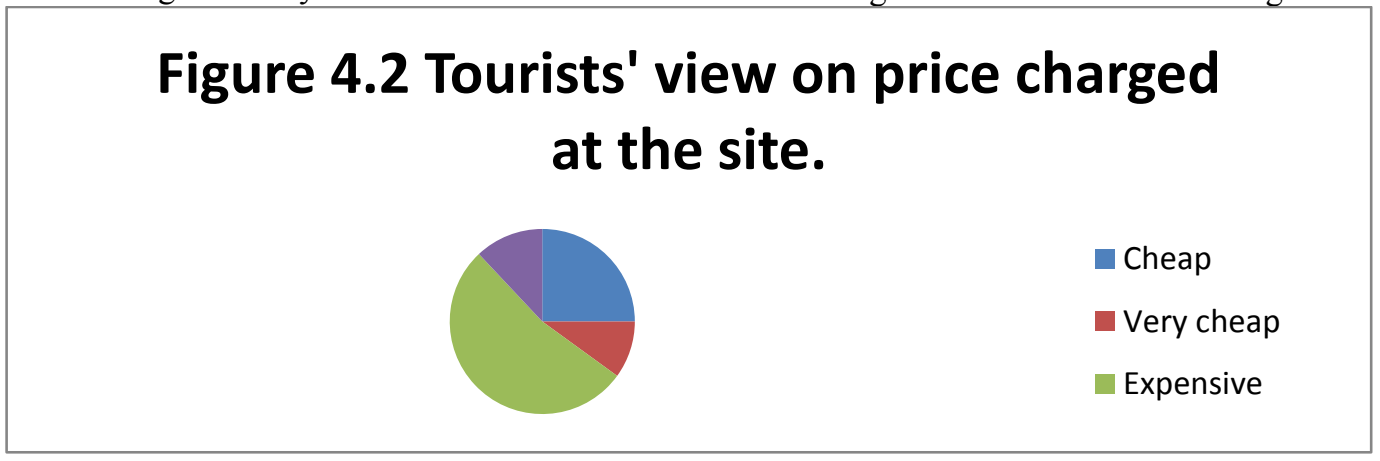

From the above figure, the majority of tourists viewed the site as expensive $(53 \%)$ while a quarter viewed it as cheap (25\%). It is evident therefore to say that the site appeared expensive to the most tourists who visited it.

According to Goffi, Cucculelli, and Masiero (2019), tourism strategies should be tourist demand focused and based on the resources of the destination so as to create a sustainable tourism development. Increasing admission prices can have a double benefit by increasing revenue for preservation efforts. However, this can discourage tourists who are price sensitive from visiting the site as observed in the study.

\subsubsection{Tourists' rate on motivating factors to} visit the site

Figure 4.3 below indicates the motivating factors to visit cultural site according to tourists' rating. This was to find out what motivated tourists to tour the site. 


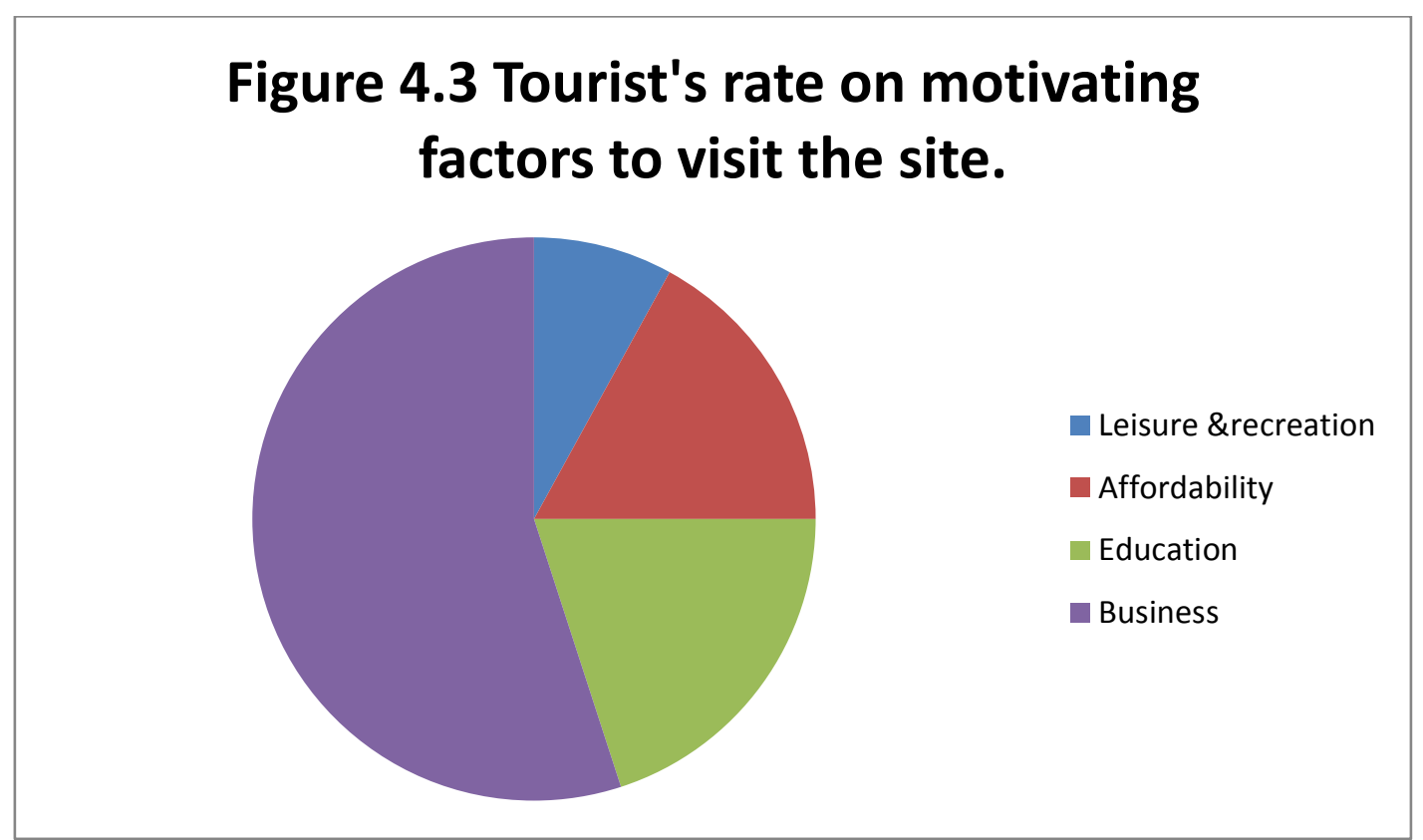

From figure 4.3 above, most tourists visited the site because of business $(55 \%)$ at the site while less than a quarter visited the site for leisure and recreation purposes $(8 \%)$. Very few numbers of tourists visited the site for education (20\%) and affordability (17\%) purposes. It is evident therefore to say that the price charged at the site was not encouraging to most of the tourists visiting the site.

\subsection{Effectiveness of brand awareness on} enhancing cultural tourism

Effectiveness of brand awareness findings of cultural site are based on Tourists' distinction of cultural site from any other, Tourists' appreciation from the site. The data was collected from Tabaka soapstone cultural site.

\subsubsection{Tourists' distinction of cultural site} from others

Table 4.8 below outlines the number of tourists who were able and unable to differentiate the cultural site from any other site. This was to find out whether tourists understood the tourism products and activities offered at Tabaka soapstone.

Table 4.8 Tourists' distinction of cultural site from others

Number of tourists who were Number of tourists who were Total able to distinguish the site unable to distinguish the site

$\frac{15(25 \%)}{\text { From table } 4.8 \text { above three quarter of tourists }}$
$(75 \%)$ were not able to distinguish the cultural site from others. Only a quarter of tourists $(25 \%)$ were able to distinguish the cultural site from any other. It is evident therefore, to say that the cultural site's attractions and activities were not well communicated to the tourists
4.4.2 Tourists' appreciation from the site

Figure 4.4 below outlines the channel through which tourists had received appreciation through the site's management. This was to find out whether the tourists got appreciation after visiting the site. 


\section{Tourists' appreciation from the site.}

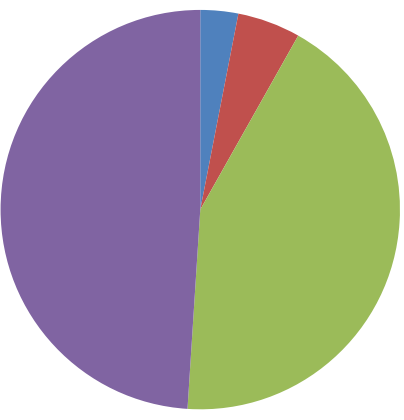

Email

Phone call
From the figure 4.4 above, majority of tourists never received appreciation (48\%). Only $42 \%$ of tourists received appreciation through word of mouth while $5 \%$ of tourists received through phone call and 3\% through Email. It is evident therefore to say that the cultural site management did not put appropriate measures to ensure all tourists received recognition. This would have enhanced repeat of visitation by the tourists to the site.

\subsubsection{Communication of site's marketing} strategy by management to employees

Table 4.9 below indicates number of employees in regard to how well the site's marketing strategy was communicated to them. This was to find out whether employees were involved in formulating the site's marketing strategies.

Table 4.9 Communication of site's marketing by management to employees

Rate Number of employees Percentage

\begin{tabular}{ll}
\hline Very well & 5 \\
Well & 15 \\
Poor & 30 \\
Very poor & 10 \\
Total & 60 \\
\hline
\end{tabular}

From table 4.9 above, half of the employees $(50 \%)$ rated communication of the marketing strategy by management to them as poor while a quarter of employees $(25 \%)$ rated it as well communicated to them. Few tourists rated communication of the marketing strategy as very well $(8 \%)$ communicated. It is, therefore, evident to say that management at the site had not involved the employees in the formulation of the marketing strategy.

\subsection{Findings of interviewee on effectiveness of marketing strategies}

The study sort to find out the feelings of the interviewee on various issues concerned with the effectiveness of marketing strategies on enhancing cultural tourism in the Kisii region. The study found the following from the interviewees:

\subsubsection{Challenges experienced in implementing marketing strategies.}

According to the cultural site management, most tourists who visited the site were price-conscious and thus spend less at the site. This, therefore, posted a great challenge to the site management as it had to consistently develop innovative travel packages and new products to attract valued-oriented tourists.

Changes in technology, according to the cultural site management created this tough competition with other cultural sites in western Kenya, as new technology had facilitated a platform for unlimited choices, where tourists tailor-make their desired experiences. This had led to the formulation of new strategies to meet tourists' demands. Most of the tourists had not inculcated the culture of traveling to the site. The management of cultural sites highlighted the instances where the tourists who had visited the site most, had only traveled twice to this site. This showed that most of the tourists had not identified themselves with the cultural site's brand. 


\subsubsection{What the cultural site management} should do on site's awareness

According to the management of the cultural site, management should frequently update new activities on its website and encourage tourists to use Facebook and twitter while providing their compliments, complaints, and views in regard to the site. Therefore, it can be concluded that employing new technology on the cultural site would enhance communication between the site and tourists thus increasing the number of tourists visiting the site.

\section{SUMMARY OF THE FINDINGS, RECOMMENDATIONS AND CONCLUSION}

This section attempts to summarize the key findings of the study. It also gives the conclusion as well as the recommendations in regard to the problem under investigation.

\subsection{SUMMARY OF THE STUDY}

The purpose of this study was to identify the effectiveness of marketing strategies on enhancing Cultural Tourism in Kisii region. The results were analyzed depending on the objectives of the study.

\subsubsection{Effectiveness of promotion on enhancing cultural Tourism}

From the information collected it was evident that an inadequate number of tourists visiting the cultural site is due to ineffective promotion techniques used. The study aimed at identifying the effectiveness of promotion on enhancing cultural tourism in the area of study. The study underscored tourists' motivations for the site. This was to find whether the message conveyed out to tourists in regard to attractions and activities was effective. It was found out that the majority of tourists visited the site for business purposes. This meant that the cultural site's attractions and activities had not been communicated well to the target tourists. It was found that the majority of tourists that visited the site were not satisfied with the services offered. Only a quarter of tourists felt satisfied with services. It was therefore concluded that tourism products and services were not well presented to tourists as they were promised to them before.

According to professor Kieyah of the institute of public policy Research and Analysis of Kenya, there had been a definite vacuum in the regulation of consumer matters (Daily Nation, 2013). He argued that the enactment of the consumer protection act, 2012 was to provide a solution towards protecting consumers from exploitation by the organization. The act encouraged the representation of consumers when designing products so as to ensure that the products developed met customers' needs. The involvement of tourists in designing and presenting cultural products at the site could have led to more satisfaction in terms of quality and price charged.

\subsubsection{Effectiveness of price on enhancing cultural tourism}

The study found that the cultural site had not put measures to attract tourists during weekdays as most of the tourists visiting the site during holidays and weekends. From the information collected majority of tourists viewed the site as expensive while less than a quarter viewed it as cheap. It was evident therefore to say that the site appeared expensive to most tourists.

GOK (2018) designed a strategy that aimed at encouraging civil servants to travel to local tourist destinations. It thought of countering tourism seasonality that had greatly affected the tourism industry by giving travel incentives to its employees. Most cultural sites including Tabaka had been receiving a low number of tourists during weekdays but this is likely to change due to outlined policy by the government. From the study, the cultural site should provide offers that are attractive to civil servants especially during weekdays in order to motivate them to visit the site.

\subsubsection{Effectiveness of brand awareness on enhancing cultural tourism}

It was found that tourists were unable to differentiate the cultural site from others. This showed that the site's logo had not been well designed and communicated to tourists. The majority of tourists did not receive appreciation after visiting the site. This revealed that the site had not inculcated the culture of recognizing tourists. The site should, therefore, be made unique by making the logo clear on brochures, websites, and signboards and also create a good relationship with tourists.

According to Kim, Choe, and Petrick (2018) brand awareness rely on several factors based on loyalty, perceived quality, associations, and awareness. From the study, it can be observed that the cultural site had not formed effective relationships by the tourists and therefore this had led to a low repeat of visitation at the site.

\subsection{Recommendation}

The cultural site management should identify appropriate communication techniques that would reach more target tourists. It should encourage use of website and local radio station to enable more target tourists discover the site instead of tourists depending on friends and relatives as revealed by the study. 
Proper description of tourism products and services should be done when presenting such products and services to target tourists. The message conveyed to tourists in regard to attractions and activities should be accurate and detailed. From the study it was evident that most of tourists visited the site for business purposes that involved buying soapstone instead of carrying out non-consumptive activities.

Tourists should be promised on what they will find at the site on their arrival at the site. Most of tourists under study felt unsatisfied with the products and services offered to them. This might have been as a result of providing tourists with a lot of expectations before arrival.

Offers and discounts during week days should be encouraged in order to enhance visitation during such periods. From the study, majority of tourists visited during weekends. Provision of such offers and discounts would reduce overcrowding of tourists during weekends on attractions thus avoiding degradation of such attractions.

Prices charged on Tourism products at the site should be harmonized to reduce the perception by many tourists as expensive. This will encourage many tourists to travel to the site as they will see the site as affordable.

The site should be differentiated from others through making site's logo clear on brochures and websites. This would enable tourists to identify themselves with the site and visit it again.

Employees should be involved in formulating marketing strategies. This will enable them easily implement such strategies to meet tourists needs and wants thus satisfying them. Appropriate communication of formulated strategies to employees will enable them deliver them effectively.

\subsection{CONCLUSION}

From the finding of this study it was concluded that effective promotion should entail proper conveying of messages and adequate delivery of tourism products and services as it was promised to target tourists. This will enable tourists discover the site and tourism products presented to them. It was also concluded that while pricing tourism products, great consideration should be given to tourists' view on price so as to encourage many tourists to visit the site. Products and services offered to the tourists visiting the site should be enhanced and personalized so as to differentiate the site from others. Price sensitivity of tourists that appeared to be the great challenge to management as observed from the study should be addressed by consistently innovating travel packages and new products to attract valued-oriented tourists. The study farther concluded that in order to differentiate the cultural site from others, site's logo on sign boards and brochures should be made clear to tourists. Long term relationship development between tourists and cultural site should be enhanced through frequent recognition of visiting tourists. This will encourage repeat of visitation. New technology should be an opportunity to cultural site rather than a challenge as it was found in the study.

\section{REFERENCES}

1. AlGarni, K. (2020). Special Forms of Tourism: A Global View. Hospitality \& Tourism Review, 1(1), 23-32.

2. Almeyda-Ibáñez, M., \& George, B. P. (2017). The evolution of destination branding: A review of branding literature in tourism. Journal of Tourism, Heritage \& Services Marketing, 3(1), 9-17.

3. Bassano, C., Barile, S., Piciocchi, P., Spohrer, J. C., Iandolo, F., \& Fisk, R. (2019). Storytelling about places: Tourism marketing in the digital age. Cities, 87, 10-20.

4. Camilleri, M. A. (2018). Integrated marketing communications. In Travel marketing, tourism economics and the airline product (pp. 85-103). Springer, Cham.

5. Chen, H., \& Rahman, I. (2018). Cultural tourism: An analysis of engagement, cultural contact, memorable tourism experience and destination loyalty. Tourism Management Perspectives, 26, 153-163.

6. Daily Nation. (2013, March 25). New law makes the Kenyan consumer king. Daily Nation. Kenya. Retrieved from https://www.nation.co.ke/lifestyle/smartcompany/C onsumers-win-under-new-law/1226-1730090pkqlekz/index.html

7. Diarta, I. K. S. (2017). Promotion strategy of Borobudur world cultural heritage site for international tourists. Udayana Journal of Social Sciences and Humanities, 1(2), 190.

8. Ei, T., \& Karamanis, K. (2017). The evolution of alternative forms of Tourism: a theoretical background. Business \& Entrepreneurship Journal, 6(1), 1-4.

9. Fader, P. (2020). Customer centricity: Focus on the right customers for strategic advantage. Wharton digital press.

10. Faith, D. O., \& Agwu, P. E. (2018). A review of the effect of pricing strategies on the purchase of consumer goods. International Journal of Research in Management, Science \& Technology (E-ISSN: 2321-3264) Vol, 2.

11. Foroudi, P., Cuomo, M. T., Foroudi, M. M., Katsikeas, C. S., \& Gupta, S. (2020). Linking identity and heritage with image and a reputation for competition. Journal of Business Research, 113, 317-325. 
12. Foroudi, P., Gupta, S., Kitchen, P., Foroudi, M. M., \& Nguyen, B. (2016). A framework of place branding, place image, and place reputation. Qualitative Market Research: An International Journal.

13. Gibbs, C., Guttentag, D., Gretzel, U., Yao, L., \& Morton, J. (2018). Use of dynamic pricing strategies by Airbnb hosts. International Journal of Contemporary Hospitality Management.

14. Goffi, G., Cucculelli, M., \& Masiero, L. (2019). Fostering tourism destination competitiveness in developing countries: The role of sustainability. Journal of cleaner production, 209, 101-115

15. Government of Kenya (2018). Kenya Tourism Agenda 2018 - 2022. Government of Kenya Ministry of Tourism and Wildlife. Retrieved from http://www.tourism.go.ke/wpcontent/uploads/2018/06/Agenda-18-22-Final4Launch.pdf

16. Government of Kenya. (2020). Heritage activities. The Ministry of Sports, Culture and Heritage. Retrieved from http://sportsheritage.go.ke/

17. Hamed, H. M. (2017). Marketing destinations to millennials: Examining the compatibility between the destination marketing organization website and the millennial tourist prospects. Journal of Tourism and Recreation, 3(1), 1-20.

18. Kim, S. S., Choe, J. Y. J., \& Petrick, J. F. (2018). The effect of celebrity on brand awareness, perceived quality, brand image, brand loyalty, and destination attachment to a literary festival. Journal of Destination Marketing \& Management, 9, 320-329.

19. Kock, N., \& Hadaya, P. (2018). Minimum sample size estimation in PLS-SEM: The inverse square root and gamma-exponential methods. Information Systems Journal, 28(1), 227-261.

20. Lancaster, K. (2017). Confidentiality, anonymity and power relations in elite interviewing: conducting qualitative policy research in a politicised domain. International Journal of Social Research Methodology, 20(1), 93-103.

21. Li, Y., Hu, C., Huang, C., \& Duan, L. (2017). The concept of smart tourism in the context of tourism information services. Tourism Management, 58, 293-300.

22. Lutz, C., \& Newlands, G. (2018). Consumer segmentation within the sharing economy: The case of Airbnb. Journal of Business Research, 88, 187196.

23. Morrison, A. M. (2018). Marketing and managing tourism destinations. Routledge

24. Neuts, B. (2020). Mixed pricing strategies in museums: Examining the potential of voluntary contributions for capturing consumer surplus. Tourism Economics, 26(1), 115-136.

25. Novais, M. A., Ruhanen, L., \& Arcodia, C. (2018). Destination competitiveness: A phenomenographic study. Tourism management, 64, 324-334.
26. Riddhagni, N., \& Taylor, K. (2019). Cultural Tourism and Architecture Heritage: Question of Authenticity (Doctoral dissertation, Silpakorn University).

27. Steinmetz, J.T. (2020, January 10). Kenya Tourism Sector Performance Report 2019. E Turbo News: Global Travel Industry News. Retrieved from https://www.eturbonews.com/539335/kenyatourism-sector-performance-report-2019/

28. United Nations World Tourism Organization. (2020 January 19). Growth in international tourist arrivals continues to outpace the economy. World Tourism Organization. Retrieved from https://www.unwto.org/world-tourism-barometern18-january-2020

29. Walker, K., \& Moscardo, G. (2016). Moving beyond sense of place to care of place: the role of Indigenous values and interpretation in promoting transformative change in tourists' place images and personal values. Journal of Sustainable Tourism, 24(8-9), 1243-1261. 